\title{
JNVESTJGAACJÓN
}

\section{The oleic acid esterification of policosanol increases its bioavailability and hypocholesterolemic action in rats}

\author{
By D. Haim ${ }^{a, c,}$, A. Valenzuela ${ }^{b, c}$, M. C. Brañes ${ }^{d}$, M. Fuenzalida $^{d}$ and L. A. Videla ${ }^{a}$ \\ ${ }^{a}$ Molecular and Clinical Pharmacology Program, Institute of Biomedical Sciences, \\ Faculty of Medicine, University of Chile, Santiago, Chile (DH, and LAV) \\ ${ }^{\mathrm{b}}$ Laboratory of Lipids and Antioxidants, Institute of Nutrition and Food Technology, \\ University of Chile, Santiago, Chile (AV) \\ ${ }^{\circ}$ Faculty of Medicine, University of the Andes, Santiago, Chile (DH, and AV); \\ ${ }^{\mathrm{d}}$ Naturalis S.A., Santiago, Chile (MCB, and MF) \\ ${ }^{*}$ Corresponding author: dnhaim @ miuandes.cl
}

\section{RESUMEN}

La esterificación de ácido oleico en policosanoles aumenta su biodisponibilidad y el efecto hipocolesterolémico en ratas

Los Policosanoles están formados por una mezcla de alcoholes alifáticos de cadena larga y se obtienen de las ceras de la caña de azúcar. Más de cincuenta estudios indican que los policosanoles reducen el colesterol sérico, mientras que otros no logran reproducir este efecto. El objetivo de esta investigación fue evaluar la biodisponibilidad de policosanoles esterificados y no esterificados (NEP), en relación con sus efectos hipocolesterolémicos. Para ello, a ratas Sprague Dawley se les administró una dosis oral diaria de $100 \mathrm{mg} \mathrm{kg}^{-1}$ de NEP, $117 \mathrm{mg} \mathrm{kg}^{-1}$ de policosanoles esterificados con ácido butírico (BAEP), ó $164 \mathrm{mg} \mathrm{kg}^{-1}$ de policosanoles esterificados con ácido oleico (OAEP). La absorción de los policosanoles se evaluó en el plasma entre 0 y 3 horas después de la ingestión. Para evaluar los cambios en el colesterol total, colesterol-LDL, colesterol-HDL y triglicéridos en el plasma y en la fosforilación de la hígado 3-hidroxi-3-metilglutaril coenzima A reductasa (HMG-CoA red), la ingesta de las ratas fue suplementada con policosanoles no esterificados o esterificados durante 5 semanas. Los resultados indicaron que la absorción de los policosanoles fue significativamente mayor en las ratas tratadas con los OAEP que en las sometidas a los NEP o las que se les administró BAEP. Los OAEP redujeron significativamente el colesterol plasmático total y el colesterol-LDL de las ratas, además de aumentar 5.6 veces $(P<0,05)$ sobre los valores control, en el contenido hepático de la HMG-CoA fosforilada red. En conclusión, la esterificación de policosanoles con ácido oleico aumenta la biodisponibilidad de los policosanoles, y mejora significativamente el perfil de lípidos séricos en ratas normocolesterolémicos en asociación con la inactivación de la colesterogénesis control HMG-CoA red.

PALABRAS-CLAVE: Absorción de Policosanoles - Biodisponibilidad - Efecto reductor de colesterol - Octacosanol - Policosanol - Triacontanol - Ratas.

\section{SUMMARY}

The oleic acid esterification of policosanol increases its bioavailability and hypocholesterolemic action in rats

Policosanol comprises a mixture of long-chain aliphatic alcohols from sugarcane wax. More than 50 studies indicate that policosanol decreases serum cholesterol, while others failed to reproduce this effect. The objective of this investigation was to assess the bioavailability of esterified policosanol and non-esterified policosanol (NEP), in relation to their hypocholesterolemic effects. Sprague Dawley rats were given a daily oral dose of $100 \mathrm{mg} / \mathrm{kg}$ of NEP, $117 \mathrm{mg} \mathrm{kg}^{-1}$ of butyric acid esterified policosanol (BAEP), or $164 \mathrm{mg} \mathrm{kg}^{-1}$ of oleic acid esterified policosanol (OAEP). Policosanol absorption was evaluated in plasma between 0 and 3 hours after ingestion. To assess changes in total cholesterol, LDL-cholesterol, HDLcholesterol and triacylglycerols in plasma and liver 3-hydroxy3-methylglutaryl coenzyme A reductase (HMG- CoA red) phosphorylation, the rats were supplemented with nonesterified or esterified policosanol for 5 weeks. The results indicate that policosanol absorption was significantly greater in OAEP-treated rats than in those subjected to NEP or BAEP administration. OAEP significantly reduced plasma total and LDL-cholesterol in rats, in addition to a 5.6-fold increase $(P<0.05)$ in the hepatic content of phosphorylated HMG-CoA red over the control values. In conclusion, esterification of policosanol with oleic acid enhances policosanol bioavailability, and significantly improves the serum lipid profile in normocholesterolemic rats in association with the inactivation of HMG-CoA red controlling cholesterogenesis.

KEY-WORDS: Bioavailability - Cholesterol lowering effect - Octacosanol - Policosanol - Policosanol absorption - Rats - Triacontanol.

\section{INTRODUCTION}

Coronary heart disease is a leading cause of death in industrialized nations, with elevated levels of total serum cholesterol, low density lipoprotein 
(LDL)-cholesterol, and triglycerides, as important cardiovascular risk factors (Singh and Mehta, 2002). Policosanol, a mixture of primary aliphatic alcohols originally derived from sugarcane wax (Saccharum officinarum) (Janikula, 2002), in which octacosanol (63\%), triacontanol (13\%) and hexacosanol $(6 \%)$ prevail (Gouni-Berthold et al., 2002), effectively improves serum lipid profiles. This effect was shown in animal models (Menéndez et al., 1996; Arruzazabala et al., 2000), healthy human subjects (Hernández et al., 1992), and patients with either type II hypercholesterolemia (Pons et al., 1992; Batista et al., 1996; Mas et al., 1999; Castaño et al., 2001), type II diabetes (Torres et al., 1995; Crespo et al., 1999), or postmenopausal women (Castaño et al., 2000). Interestingly, $10 \mathrm{mg}$ of this mixture had similar efficacy to an equivalent dose of statins in lowering the serum LDL concentrations (Castaño et al., 1999; Prat et al., 1999), and its supplementation caused a significant increase in the fecal excretion of neutral and acidic sterols in hamsters ( $\mathrm{Ng}$ et al., 2005), whereas octacosanol administration to humans decreased bile acid concentration in feces (Keller and Gimmler, 2008). Various studies have suggested an inhibition of the enzyme which limits the cholesterogenic route, 3-hydroxy-3-methylglutaryl coenzyme A reductase (HMG-CoA red) (Singh et al., 2006; Menendez et al, 2001; Oliaro-Bosso et al., 2009), as the mechanism of action of policosanol hypocholesterolemic activity. However, recent clinical trials failed to show significant effects. In fact, no changes in lipid variables in subjects receiving policosanol were reported (Greyling et al., 2006; Berthold et al., 2006; Dulin et al., 2006; Kassis and Jones, 2006) and neither primary hypercholesterolemic subjects (Francini-Pesenti et al., 2008a) nor diet-resistant hypercholesterolemic patients (Francini-Pesenti et al., 2008b) were affected by policosanol treatment for 8 weeks.

In the context of bioavailability of policosanols, few investigations have been performed. In nature, fatty alcohols comprising policosanol are esterified (wax), but the extraction process releases the fatty alcohols from the wax (Haim and Videla, 2008). These forms of non-esterified policosanol (NEP) were used in all the reported studies, including those of bioavailaibility assessment (Marrero and González-Bravo, 2001; Menéndez et al., 2005). These two reports involve validation of an analytical method using a maximum octacosanol plasma concentration of $14 \mathrm{ng} \mathrm{mL}^{-1}$ after a single oral dose of $40 \mathrm{mg}$ policosanol kg-1 (Marrero and Gonzalez-Bravo, 2001) and an in vivo study of octacosanol metabolism detecting $30 \mathrm{ng}$ octacosanol $\mathrm{mL}^{-1}$ plasma after a $60 \mathrm{mg} / \mathrm{kg}$ dose (Menéndez et al., 2005), thus revealing a rather low absorption of policosanol given as non-esterified compounds. In view of these considerations, we have hypothesized that a potential explanation for the discrepancies reported in the field may be related to the insufficient absorption of NEP. Consequently, the aims of this study were to determine the role of policosanol esterification in the bioavailability and hypocholesterolemic effect of these compounds in rats. For these purposes, first, pharmacokinetic studies of policosanol administered as (i) NEP, (ii) butyric acid esterified policosanol (BAEP), and (iii) oleic acid esterified policosanol (OAEP) were assessed by quantifying plasma octacosanol, triacontanol, and their main metabolites in vivo (octacosanoic acid and triacontanoic acid) after a single oral dose. Then, total cholesterol, LDLcholesterol, and HDL-cholesterol concentrations in plasma were determined in rats supplemented with non-esterified and esterified policosanol for 5 weeks, in addition to the hepatic content of total and phosphorylated HMG-CoA red controlling cholesterogenesis.

\section{MATERIALS AND METHODS}

\subsection{Synthesis of esterified policosanol}

Preparation of BAEP and OAEP. A policosanol mixture of $96 \%$ purity $(62 \%$ octacosanol, $19 \%$ triacontanol) was purchased from Pharmapia International (Shanghai, China). Fatty acids, butyric acid $(99 \%)$ and oleic acid $(90 \%)$, were purchased from Sigma Aldrich Co. (St. Louis, MO, USA). The preparations of BAEP and OAEP were made by mixing policosanol with the respective fatty acid (20\% excess related to policosanol) in the presence of $0,5 \%$ sulfuric acid (J.T. Baker, Phillipsburg, NJ, USA) at $150^{\circ} \mathrm{C}$. The concentration of NEP in the products of the reaction was less than $2 \%$ (detected by gas chromatography (model 7890A, Agilent Technologies, California, USA) coupled with an inert mass spectrometry detector (model 5975C, Agilent Technologies, California, USA)).

Purification of esterified policosanol. The products of the esterification reaction were subjected to neutralization with $\mathrm{KOH}$ (J.T. Baker, Phillipsburg, NJ, USA) dissolved in ethanol/distilled water (1/1) for $1 \mathrm{~h}$ at $30^{\circ} \mathrm{C}$ (ethanol was purchased from Merck KGaA, Darmstadt, Germany). Then the sample was subjected to liquid-liquid (distilled waterheptane) separation, removing the organic phase which contained the esterified policosanol (heptane was purchased from Merck KGaA, Darmstadt, Germany). Qualitative and quantitative analyses were applied to esterified policosanols, verifying the structure and proportionality of the alcohols of the mixture in the esterified product.

Preparation of the policosanol dispersions. For oral administration to rats, 3 dispersions in water at $10 \% \mathrm{p} / \mathrm{v}$ were prepared: a) NEP, b) BAEP, and c) OAEP. The surfactants used were Tween-20 and Span-85 at $5 \%$ based aqueous solution. Both surfactants were purchased from Sigma Aldrich Co. (St. Louis, MO, USA).

\subsection{In vivo studies}

Animal treatments. Male Sprague Dawley rats (Bioterio Central, Faculty of Medicine, University of 
Chile, Santiago, Chile) were kept in a temperature and light controlled room $\left(20^{\circ} \mathrm{C}\right.$ and a 12-h lightdark cycle) and fed with a standard solid diet (Alimentos Champion, Santiago, Chile) and tap water ad libitum. Rats employed for bioavailability assessment weighing 150-180 g and fasted overnight (12 h), were given a single oral dose of Tween-20/Span-85 water vehicle suspensions of NEP (100 $\mathrm{mg} \mathrm{kg}^{-1}$ body weight), BAEP (117 $\left.\mathrm{mg} \mathrm{kg}^{1}\right)$, or OAEP $\left(164 \mathrm{mg} \mathrm{kg}^{-1}\right)$. The animals used in the chronic treatment with an initial body weight of 50-70 g, received either daily oral isovolumetric amounts of Tween-20/Span-85 water vehicle suspension alone (controls) or containing NEP (100 $\mathrm{mg} \mathrm{kg}^{-1}$ ) or OAEP (164 $\mathrm{mg} \mathrm{kg}^{-1}$ ) for 5 weeks.

Blood and liver samples. Blood samples for pharmacokinetic studies and assessment of lipid parameters were taken under anesthesia (Zoletil, $1 \mathrm{~mL} \mathrm{~kg}^{-1}$ body weight, Virbac Laboratory, Carros, Francia) by exsanguinations through cardiac puncture using heparinized tubes, and plasma was obtained by centrifugation ( $800 \mathrm{~g}$ for $10 \mathrm{~min}$ at $4^{\circ} \mathrm{C}$ ) and stored at $-80^{\circ} \mathrm{C}$ in aliquots of $20 \mu \mathrm{L}$ until analysis. Liver samples were taken, frozen in liquid nitrogen, and kept at $-80^{\circ} \mathrm{C}$ for HMG-CoA red assessment. The study protocol was approved by the Bioethics Committee of the Faculty of Medicine, University of Chile (CBA \#0325 FMUCH).

\subsection{Bioavailability of policosanol and long- chain fatty acids}

Determination of plasmatic NEP. The presence of non-esterified octacosanol and non-esterified triacontanol in plasma was investigated. The determination was carried out by adding the internal standard betulin (99\% GC purity, Sigma Aldrich Co., St. Louis, MO, USA) to $100 \mu \mathrm{L}$ of plasma, followed by sample desolventization under a nitrogen stream. After exhaustive evaporation, the residue was reconstituted in $100 \mu \mathrm{L}$ of the derivatizing agent MSTFA (Sigma Aldrich Co, St. Louis, MO, USA) for $20 \mathrm{~min}$ at $80^{\circ} \mathrm{C}$. Finally $0.5 \mu \mathrm{L}$ were injected automatically into the gas chromatography (model 7890A, Agilent Technologies, California, USA) coupled with an inert mass spectrometry detector (model 5975C, Agilent Technologies, California, USA) for quantitative analysis. The chromatographic conditions were described by Haim et al. (2009).

Determination of plasmatic total policosanol and long-chain fatty acids (non-esterified + esterified analyte). Total concentrations in plasma were determined for octacosanol, triacontanol, octacosanoic acid, and triacontanoic acid. The protocol included saponification and acidification of the sample, stages that hydrolyze the esters and reconstitute the fatty acids, respectively. Therefore, the technique allowed for the measuring of esterified and non-esterified analytes present in the plasma. The detailed methodology and validation of the technique were reported by our group (Haim et al., 2009).

\subsection{Lipid analysis}

Fasting plasma samples were drawn from control rats and animals subjected to NEP or OAEP supplementation for 5 weeks. Total cholesterol, LDL-cholesterol, HDL-cholesterol and triglyceride concentrations in plasma were measured with enzymatic kits and standardized reagents (Valtek Diagnostics, Santiago, Chile), and results were expressed as $\mathrm{mg} \mathrm{dL}^{-1}$.

\subsection{Western blot analysis of HMG-CoA reductase}

Liver samples (100-500 mg) frozen in liquid nitrogen were homogenized and suspended in a buffer solution pH 7.9 containing 10 mM HEPES, 1 mM EDTA, $0.6 \%$ Nonidet P-40, $150 \mathrm{mM} \mathrm{NaCl}$, and protease inhibitors (1 $\mathrm{mM}$ phenylmethylsulfonyl fluoride, $1 \mu \mathrm{g} \mathrm{mL}^{-1}$ aprotinin, $1 \mu \mathrm{g} \mathrm{mL}^{-1}$ leupeptin, and $1 \mathrm{mM}$ orthovanadate). Soluble protein fractions $(60 \mu \mathrm{g})$ were separated on $12 \%$ polyacrylamide gels using SDS-PAGE (Laemmli, 1970) and transferred to nitrocellulose membranes (Towbin et al., 1979), which were blocked for 1 hour at room temperature with TBS-containing 5\% bovine serum albumin. The blots were washed with TBS-containing $0.1 \%$ Tween 20 and hybridized with either rabbit polyclonal antibodies for HMG-CoA red, phospho-HMG-CoA red (Ser 872) (Millipore, MA,USA), or mouse monoclonal antibody for $\beta$-actin (ICN Biomedicals, Inc., Aurora, OH, USA). After extensive washing, the antigen-antibody complexes were detected using horseradish peroxidase goat anti-rabbit lgG or goat anti-mouse IgG and a SuperSignal West Pico Chemiluminescence kit detection system (Pierce, Rockford, IL).

\subsection{Statistical analysis}

The values shown represent the mean \pm standard error of the mean (SEM) for the number of separate experiments indicated. One-way or two-way ANOVA followed by Newman-Keuls post-test assessed the statistical significance of difference among values. $P$ values $<0.05$ were considered significant. All statistical analyses were performed using GraphPad Prism software (version 4.0, GraphPad Software Inc., San Diego, CA, USA).

\section{RESULTS}

\subsection{The effect of NEP administration on non-esterified policosanol and total policosanol (non-esterified + esterified) concentrations in plasma}

The administration of NEP $\left(100 \mathrm{mg} \mathrm{kg}^{-1}\right)$ to rats did not increase the plasmatic concentrations of non-esterified alcohols, ranging from $3.79 \pm 0.40$ to $4.70 \pm 0.81 \mathrm{ng} \mathrm{mL}^{-1}$ for octacosanol (Fig. 1A) and from $1.34 \pm 0.04$ to $2.13 \pm 0.21 \mathrm{ng} \mathrm{mL}^{-1}$ for 
triacontanol (Fig. 1B), respectively. Conversely, the total policosanol in plasma significantly increased at min 60 compared with time zero (496 \pm 25 compared with $170 \pm 9 \mathrm{ng} \mathrm{mL}^{-1}$ for octacosanol (Fig. 1A) and $130 \pm 11$ compared with $27 \pm 5 \mathrm{ng} \mathrm{mL}^{-1}$ for triacontanol (Fig. 1B), respectively). Esterified policosanol concentrations were calculated as the subtraction between total and non-esterified policosanol values. At time zero (fasting plasma samples without policosanol administration), 2.3\% of total circulating octacosanol was detected as non-esterified alcohol, whereas the remaining fraction (97.7\%) represented esterified octacosanol (Fig. 1A, inset). As expected, the proportions were similar for triacontanol (5\% non-esterified and 95\% esterified alcohol) (Fig. 1B, inset). Consequently, policosanol circulates predominantly in its esterified form.

\subsection{Comparison of plasma total policosanol concentrations in rats subjected to a single dose of NEP, BAEP, and OAEP}

Fasting plasma samples were obtained after the administration of a single, oral dose of NEP, BAEP, or OAEP, and the kinetics of octacosanol (Fig. 2A), octacosanoic acid (Fig. 2B), triacontanol (Fig. 2C) and triacontanoic acid (Fig. 2D) were determined between 0 and $180 \mathrm{~min}$. According to the data presented in Fig. 1, only total policosanol concentrations were evaluated in the plasma. Analysis of the data presented in Fig. 2 shows posttreatment plasma policosanol and long-chain fatty acid response, expressed as the area under the curves at $0-3 \mathrm{~h}$ after the ingestion of the policosanol enriched dispersion (Figs. $3 \mathrm{~A}$ and $3 \mathrm{~B}$ ). The results indicate a significantly higher response in the group given OAEP $(43690 \pm 5142 \mathrm{ng}$ octacosanol $\mathrm{min}$ $\mathrm{mL}^{-1}$ for OAEP compared with $30455 \pm 2870$ for NEP and $7978 \pm 118$ for BAEP) (Fig. 3A), which is similar to that obtained for triacontanol (Fig. 3B). Also, the group treated with OAEP elicited a significantly higher peak plasma octacosanol concentration at min 60 compared with NEP and BAEP $\left(654 \pm 88 \mathrm{ng} \mathrm{mL}{ }^{-1}\right.$ for OAEP compared with $325 \pm 25$ for NEP and $65 \pm 18$ for BAEP) (Fig. 3C). Comparable results were obtained for triacontanol (Fig. 3D). Furthermore, the peak plasma concentration for long-chain fatty acids in the OAEP group were detected at $\min 60$, with octacosanoic acid being higher $(P<0.05)$ than NEP and BAEP $\left(158 \pm 19 \mathrm{ng} \mathrm{mL}^{-1}\right.$ for OAEP, $81 \pm 7$
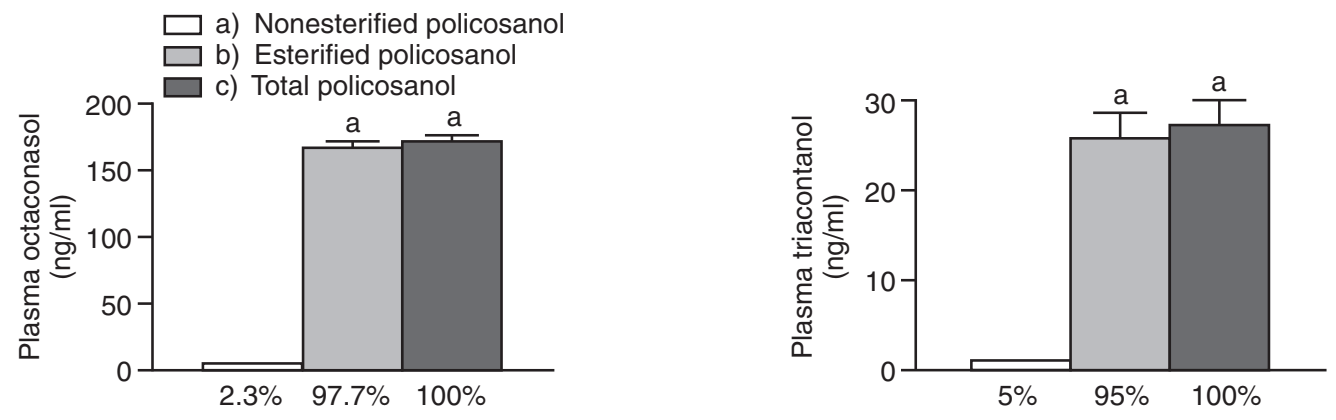

A

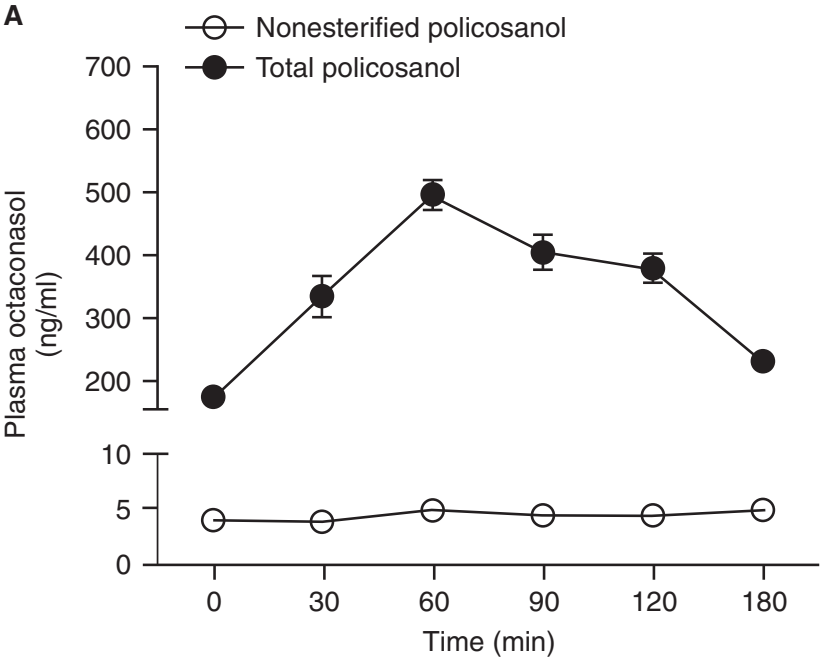

B

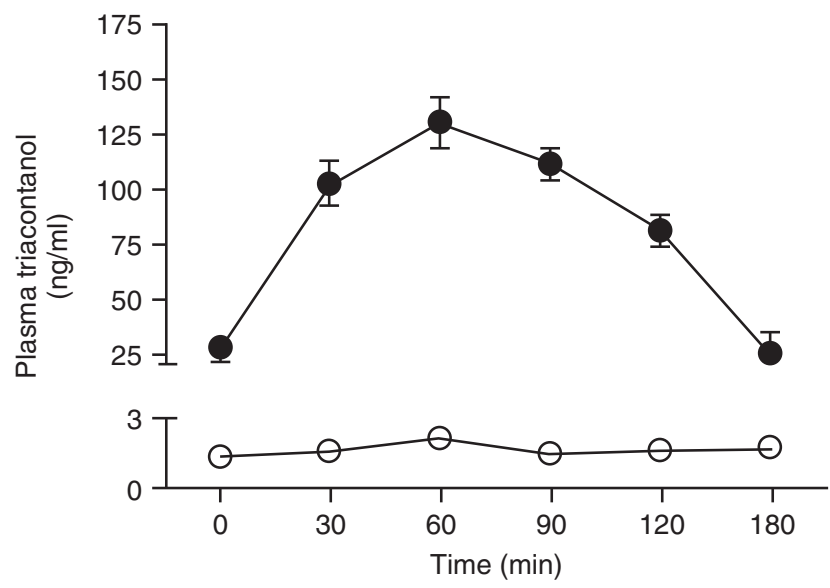

Figure 1

Plasma concentration-time profile of total and non-esterified octacosanol (A) and triacontanol (B) in rats after a single oral dose of non-esterified policosanol (100 mg/kg) given at time zero. Insets A and B correspond to non-esterified, esterified, and total octacosanol and triacontanol concentrations obtained at time zero, respectively. Data are means \pm SEM for three to five separate experiments per point. Statistical significance in insets $\mathrm{A}$ and $\mathrm{B}(P<0.05)$ is shown by the letters identifying each experimental group, assessed by one-way ANOVA followed by Newman-Keuls' post-test. 

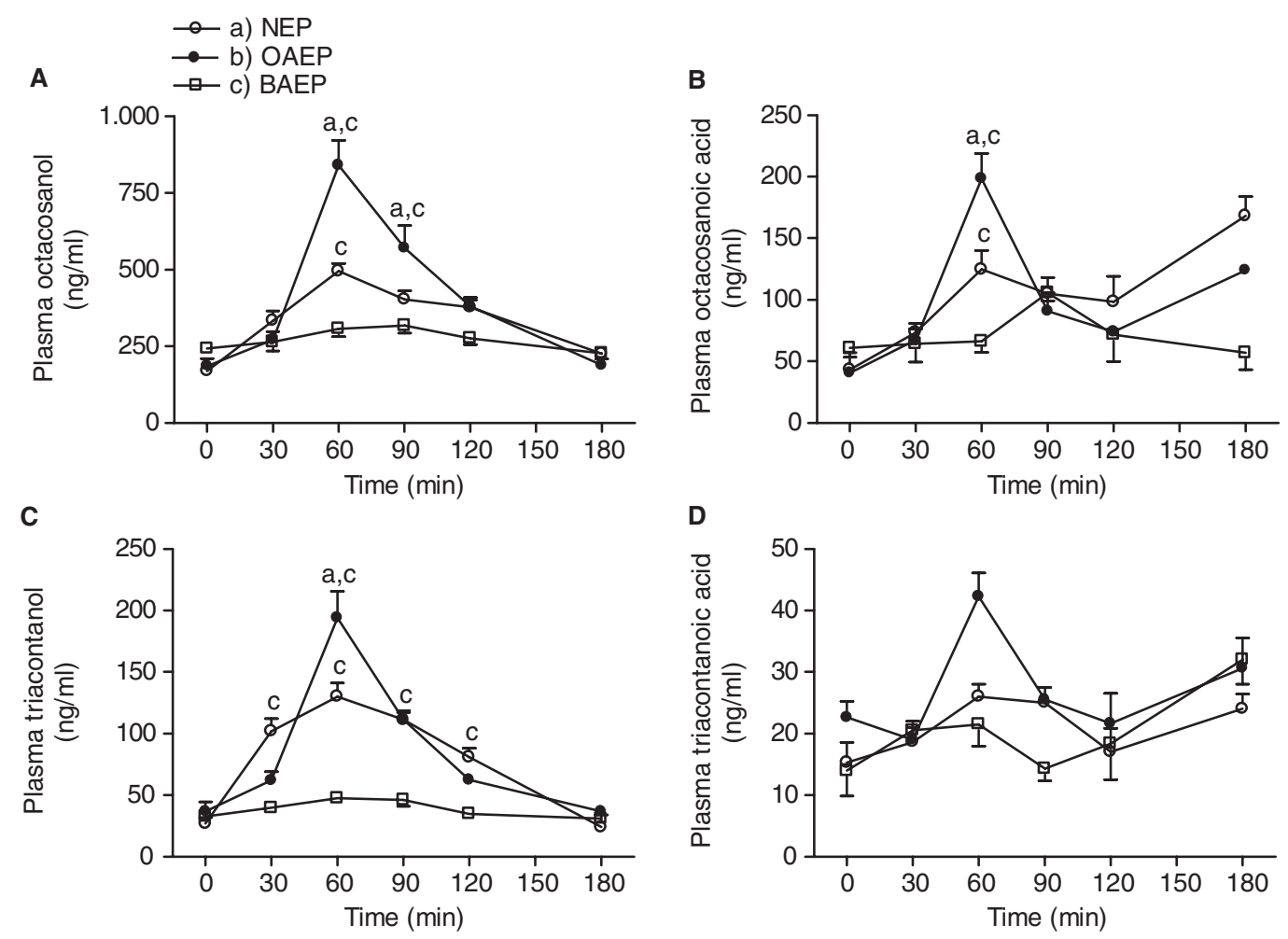

Figure 2

Plasma concentration-time profile of total octacosanol (A), octacosanoic acid (B), triacontanol (C), and triacontanoic acid (D) in rats after a single oral dose of either non-esterified policosanol (NEP; $100 \mathrm{mg} / \mathrm{kg}$ ), oleic acid esterified policosanol (OAEP; $164 \mathrm{mg} / \mathrm{kg}$ ), or butyric acid esterified policosanol (BAEP; $117 \mathrm{mg} / \mathrm{kg}$ ) given at time zero. Data are means \pm SEM for three to five separate experiments per point. Statistical significance $(P<0.05)$ is shown by the letters identifying each experimental group, assessed by two-way ANOVA followed by Newman-Keuls' post-test.

for NEP, and $5 \pm 5$ for BAEP) (Fig. 3C), whereas that of triacontanoic acid was comparable to NEP and higher than BAEP $(P<0.05)$ (Fig. 3D). Nevertheless, the variations in very long-chain fatty acid concentrations in the plasma were small in relation to the kinetics of their precursors.

\subsection{Comparison of plasma lipid concentrations in rats subjected to chronic NEP and OAEP administration}

OAEP significantly decreased both total plasma cholesterol (Fig. 4A) and LDL-cholesterol (Fig. 4B) $\left(40 \pm 2(n=8) \mathrm{mg} \mathrm{dL}^{-1}\right.$ and $\left.7 \pm 1(\mathrm{n}=8)\right)$ compared to NEP $(52 \pm 2$ and $13 \pm 2)$ and the control group $(51 \pm 1$ and $14 \pm 2)$, respectively. Conversely, plasmatic HDL-cholesterol (Fig. 4C) and triglyceride (Fig. 4D) concentrations were not modified by NEP or OAEP supplementation. The total cholesterol/ HDL-cholesterol ratio (Fig. 5A) and LDL-cholesterol/ HDL-cholesterol ratio (Fig. 5B) were significantly $(P<0.05)$ decreased by OAEP compared to the controls and the NEP-treated rats.

\subsection{Comparison of the hepatic protein content of HMG-CoA red in rats subjected to chronic NEP and OAEP administration}

The evaluation of total HMG-CoA red (phosphorylated + non-phosphorylated) in rat liver revealed comparable values in rats subjected to NEP and OAEP administration, and compared to control values (Fig. 6A). Nevertheless, phosphorylated HMGCoA red content significantly increased in the OAEP group $(2.16 \pm 0.3(n=8))$ versus the NEP group $(0.90 \pm 0.11(n=8))$ and the controls $(0.38 \pm 0.08$ $(n=6))$ (Fig. 6B).

\section{DISCUSSION}

The present investigation was focussed on the possible reasons regarding the controversy over policosanol efficacy as a hypocholesterolemic agent. Differences between the length of the study period, typical dietary habits, or ethnic diversity of the participants of clinical trials seem unlikely to be the cause of the large variation in the cholesterol lowering effects of this supplement. Nevertheless, there is agreement among the authors that a critical point that needs to be addressed is the availability of the alcohol components in the policosanol mixture, due to their poor absorption in the gut (Marrero and González-Bravo, 2001; Menéndez et al., 2005). Because the form of administration of a treatment often plays a role in determining its efficacy, the objective of this study was to evaluate policosanol chemical modifications for their absorption capacity. Considering the fact that policosanol is esterified in nature (Haim and Videla, 

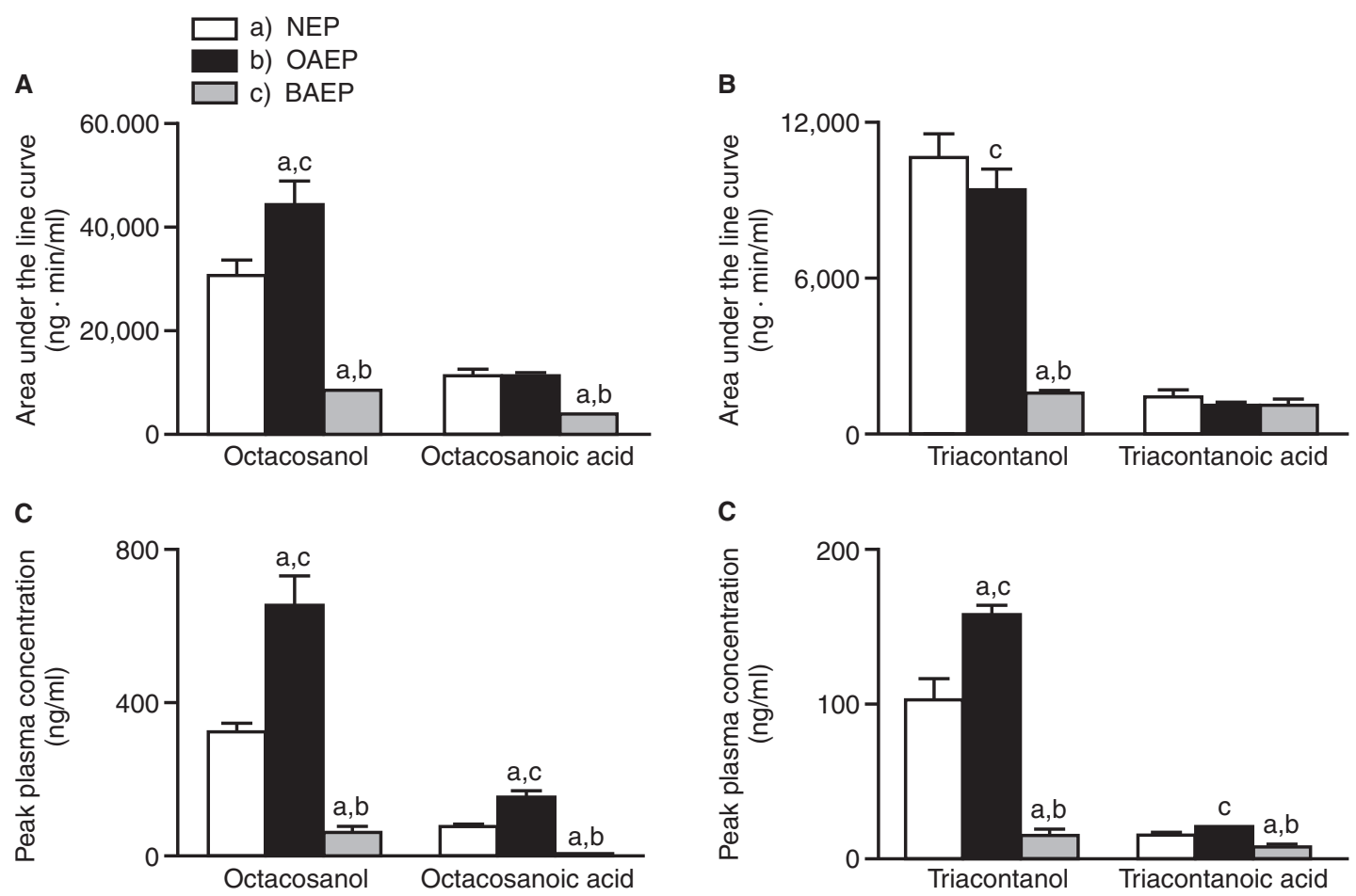

Figure 3

Area under the time curve for octacosanol and octacosanoic acid (A) and triacontanol and triacontanoic acid (B) and the respective peak plasma concentrations at $60 \mathrm{~min}(\mathrm{C}$ and $\mathrm{D})$, corrected for values at time zero, in rats after a single oral dose of either non-esterified policosanol (NEP; $100 \mathrm{mg} / \mathrm{kg}$ ), oleic acid esterified policosanol (OAEP; 164 $\mathrm{mg} / \mathrm{kg}$ ), or butyric acid esterified policosanol (BAEP; $117 \mathrm{mg} / \mathrm{kg}$ ) given at time zero (for details, see Fig. 2). Data are means \pm SEM for three to five separate experiments per point. Statistical significance $(P<0.05)$ is shown by the letters identifying each experimental group, assessed by one-way ANOVA followed by Newman-Keuls' post-test.

2008), and that phytosterols,- which are hypocholesterolemic phytochemical agents (Wu et al., 2009; Clifton, 2009) that exhibit some similar physical and chemical properties to policosanol, have demonstrated a cholesterol lowering effect when they are administered in their esterified form (Nissinen et al., 2006), we postulated that the esterification of policosanol could improve its bioavailability in relation to the non-esterified form, such as the commercial product. For this purpose, two policosanol ester families, BAEP and OAEP were synthesized, and the policosanol kinetics in plasma after a single oral dose of these esterified policosanol versus the non-esterified administrated group were compared. In addition, this work represents the first study incorporating the quantification of non-esterified, esterified, and total (esterified + non-esterified) policosanol in the blood.

Interestingly, a fraction higher than $95 \%$ of policosanol circulates as esterified alcohol in blood plasma, while $5 \%$ or less is found as NEP, proportions that were calculated from fasting rat plasma without the administration of policosanol. This difference becomes even greater after the administration of the policosanol dose. In addition, plasma concentrations of non-esterified octacosanol and triacontanol did not change after the oral dose of policosanol, regardless of the administration mode (NEP or OAEP). Therefore, only esterified policosanol concentrations increased in the blood after supplementation. The pharmacokinetic studies previously reported (Marrero and GonzálezBravo, 2001; Menéndez et al., 2005, Gonzalez-Bravo et al., 1996) did not include a saponification step of plasma extracts. For this reason, the concentrations observed represent only non-esterified circulating policosanol, which explains the low values previously reported (Marrero and González-Bravo, 2001; Menendez et al., 2005, Gonzalez-Bravo et al., 1996). Furthermore, several studies have described the hydrolysis of wax as a necessary step for the absorption of fatty alcohols and fatty acids (Hargrove et al., 2004; Place, 1992). Based on this contention, our results suggest that a major fraction of policosanol is re-esterified inside the enterocyte, in agreement with the absorption of dietary lipids such as cholesterol, in which case esterification is produced by the catalytic action of the enzyme acyl-CoA cholesterol acyltransferase (Buhman et al., 2000).

The administration of OAEP demonstrated a major bioavailability in relation to NEP, evaluated as octacosanol and triacontanol plasma concentrations at $60 \mathrm{~min}$ (maximal concentration) and the respective areas under the time-curves. This novel and important finding indicates that the esterification of policosanol with the medium-chain monounsatured fatty acid oleic acid improves absorption in the gastrointestinal tract with respect to the available market product (NEP), and might represent an alternative way of supplementing policosanol. 
Additionally, BAEP did not alter the kinetics of octacosanol or triacontanol after the ingestion of a single oral dose, demonstrating that this administration form was not bioavailable in the animal model studied. It is postulated that the difference observed between the relatively high absorption of OAEP over that of BAEP may be attributed to the high stereospecificity of pancreatic esterases in the small intestine for long/mediumchain fatty acids esters (Brockerhoff, 1970), rather than for short-chain fatty acid esters, which is the case of BAEP.

Despite the fact that the active components of a policosanol mixture are fatty alcohols, D-003, a product also derived from sugarcane wax, has been reported to exert a cholesterol lowering effect in normocholesterolemic rabbits (Mendoza et al., 2001) and in patients with hypercholesterolemia type II (Castaño et al., 2003). D-003 is constituted by long-chain fatty acids, predominantly octacosanoic acid, components that are the main metabolites produced in vivo from policosanol (Menéndez et al., 2005). Consequently, the biologically active form of policosanol may include long-chain fatty alcohols and long-chain fatty acids. These fatty acids are derived from the partial oxidation of their precursors. Taking into account these antecedents, our study considered the kinetics not only of the more abundant alcohols of the policosanol mixture (octacosanol and triacontanol), but also of the respective fatty acids produced from their metabolism (octacosanoic acid and triacontanoic acid). The long-chain octacosanoic and triacontanoic fatty acids maintained low plasma concentrations in the time period assessed, showing a tendency to increase as their precursors disappeared from circulation, results that are consistent with the metabolic pathway proposed for policosanol (Haim and Videla, 2008; Menéndez et al., 2005; Hargrove et al., 2004). Nevertheless, a proportion lower than $33 \%$ of policosanol disappearance can be explained by its metabolic conversion into the respective long-chain fatty acids. The remaining fraction of policosanol in circulation is likely to be taken up by different tissues for energetic purposes, an explanation based on the evidence of radioactively marked $\mathrm{CO}_{2}$ expiration as a terminal metabolite of octacosanol beta-oxidation in rats (Kabir and Kimura, 1993).

The data presented for the NEP group are consistent with recent studies showing the lack of policosanol effect in modifying total or LDLcholesterol (Greyling et al., 2006; Berthold et al., 2006; Dulin et al., 2006; Kassis and Jones, 2006; Francini-Pesenti et al., 2008a; Francini-Pesenti et al., 2008b; Kassis et al., 2007; Murphy et al., 2008),
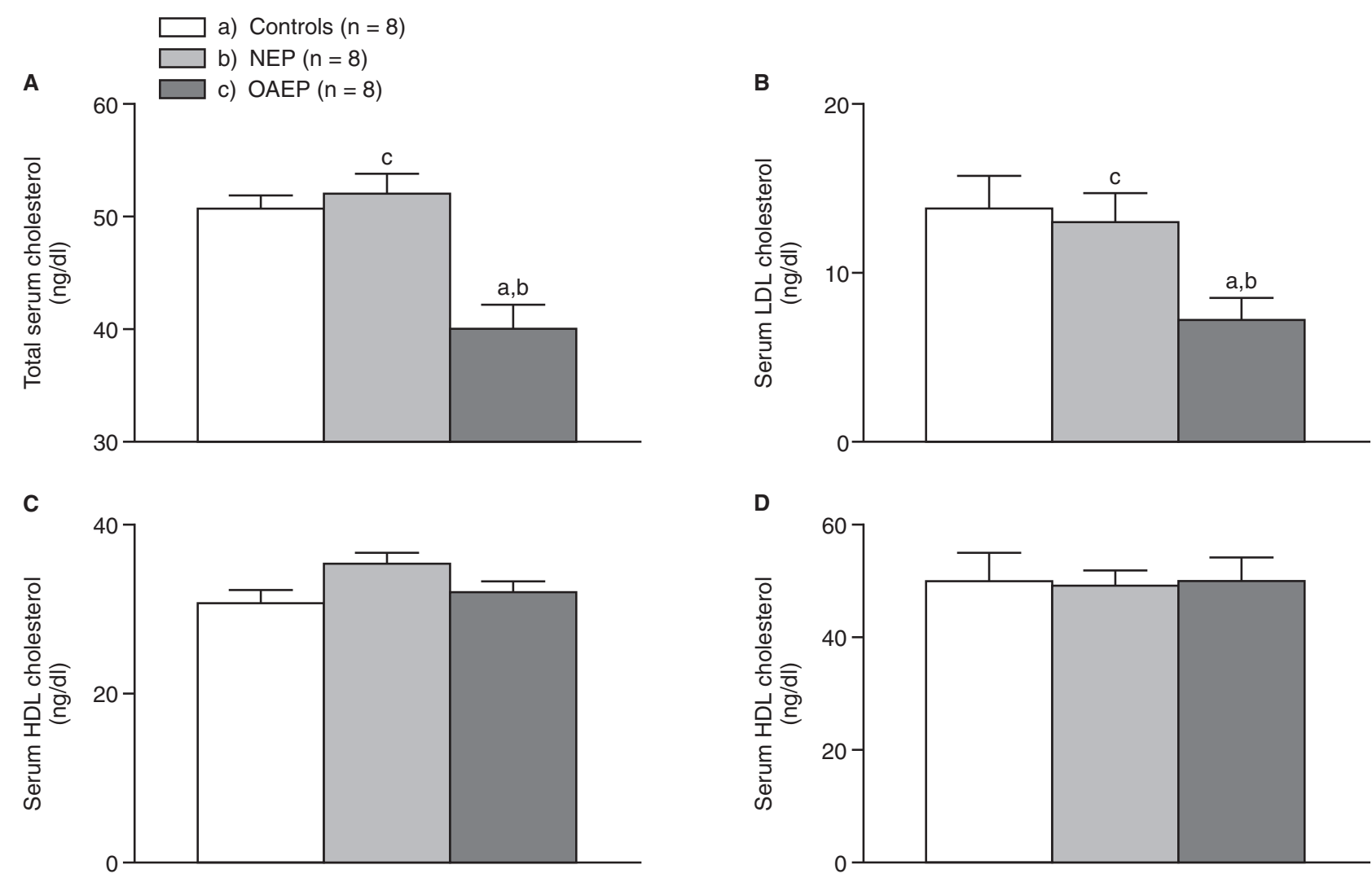

Figure 4

Plasma concentrations of total cholesterol (A), LDL-cholesterol (B), HDL-cholesterol (C), and triglycerides (D) in rats after daily administration of either vehicle for policosanol dispersion (control), non-esterified policosanol (NEP; $100 \mathrm{mg} / \mathrm{kg}$ ), or oleic acid esterified policosanol (OAEP; $164 \mathrm{mg} / \mathrm{kg}$ ) for five weeks. Data are means \pm SEM for the number of animals indicated in parentheses. Statistical significance $(P<0.05)$ is shown by the letters identifying each experimental group, assessed by one-way ANOVA followed by Newman-Keuls' post-test. 

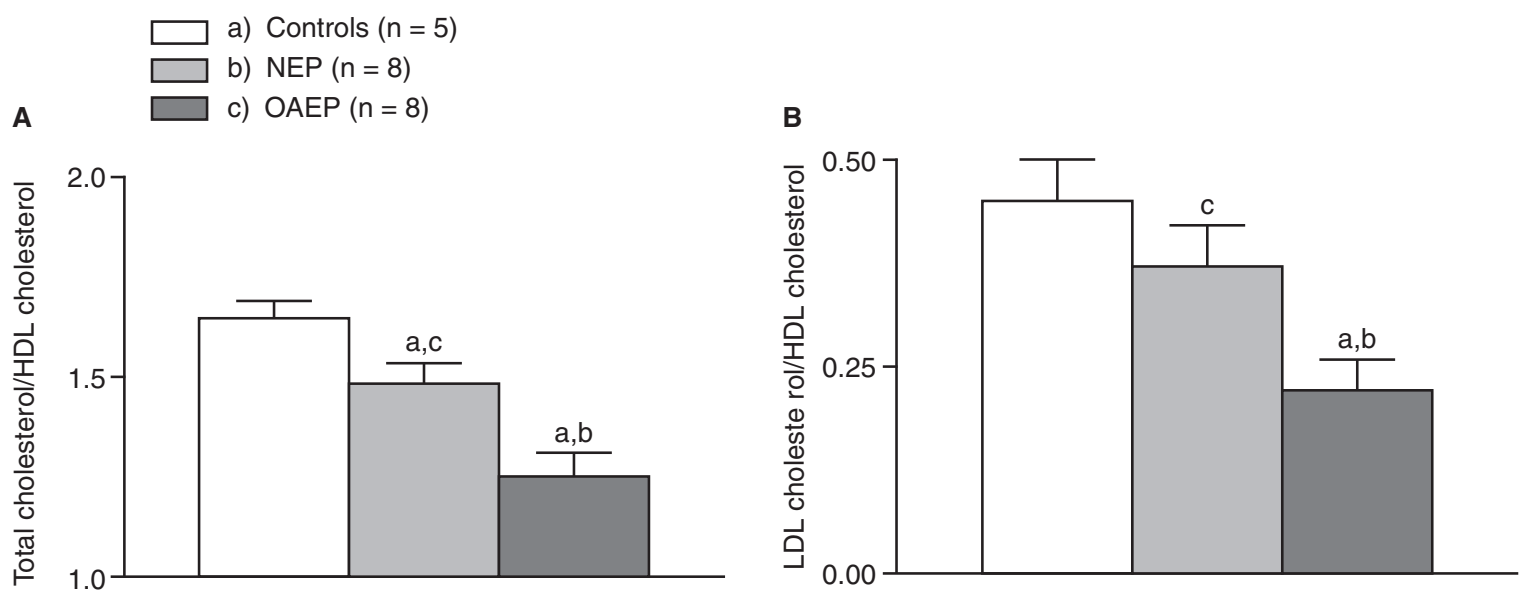

Figure 5

Total cholesterol/HDL-cholesterol and LDL-cholesterol/HDL-cholesterol ratios in rats after daily administration of either vehicle for policosanol dispersion (control), non-esterified policosanol (NEP; $100 \mathrm{mg} / \mathrm{kg}$ ), or oleic acid esterified policosanol (OAEP; $164 \mathrm{mg} / \mathrm{kg}$ )

for five weeks. Data are means \pm SEM for the number of animals indicated in parentheses. Statistical significance $(P<0.05)$ is

shown by the letters identifying each experimental group, assessed by one-way ANOVA followed by Newman-Keuls' post-test.

considering that the supplementation of rats with $100 \mathrm{mg} / \mathrm{kg}$ body weight of NEP, the same form of administration in previously reported investigations, did not alter lipid concentrations when compared to the control group. Nevertheless, the OAEP group exhibited significantly lower concentrations of plasmatic LDL-cholesterol, as the primary endpoint, and total cholesterol, as the secondary endpoint, in normocholesterolemic rats after 5 weeks of treatment. Furthermore, OAEP administration achieved significant reductions in LDL-cholesterol/ HDL-cholesterol and total cholesterol/HDL-cholesterol ratios, relationships that are of major relevance for human cholesterol homeostasis. Considering that BAEP has no effect on plasma total cholesterol and LDL-cholesterol compared to OAEP, the presence of oleic acid from OAEP after hydrolysis and absorption may play a role in lowering plasma cholesterol levels.
A

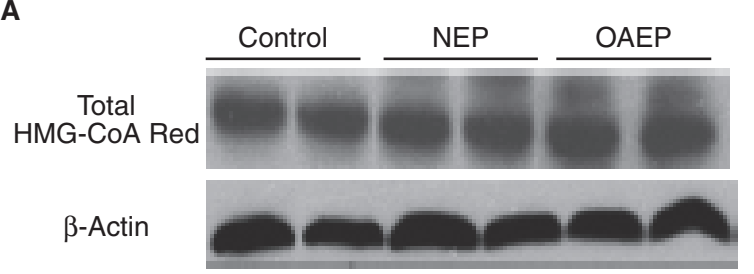

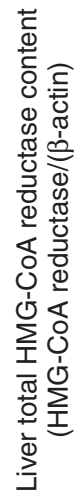

$\square$ a) Controls $(\mathrm{n}=5)$

b) NEP $(n=8)$

c) $\operatorname{OAEP}(n=8)$

1.0

$-$

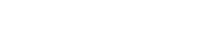

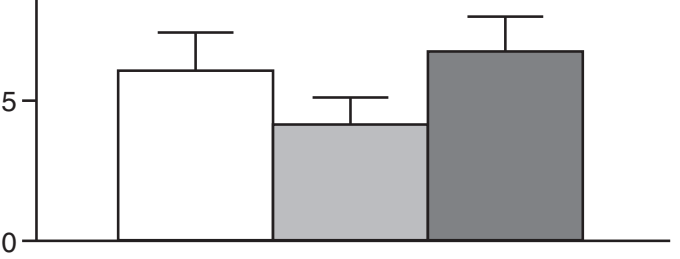

B
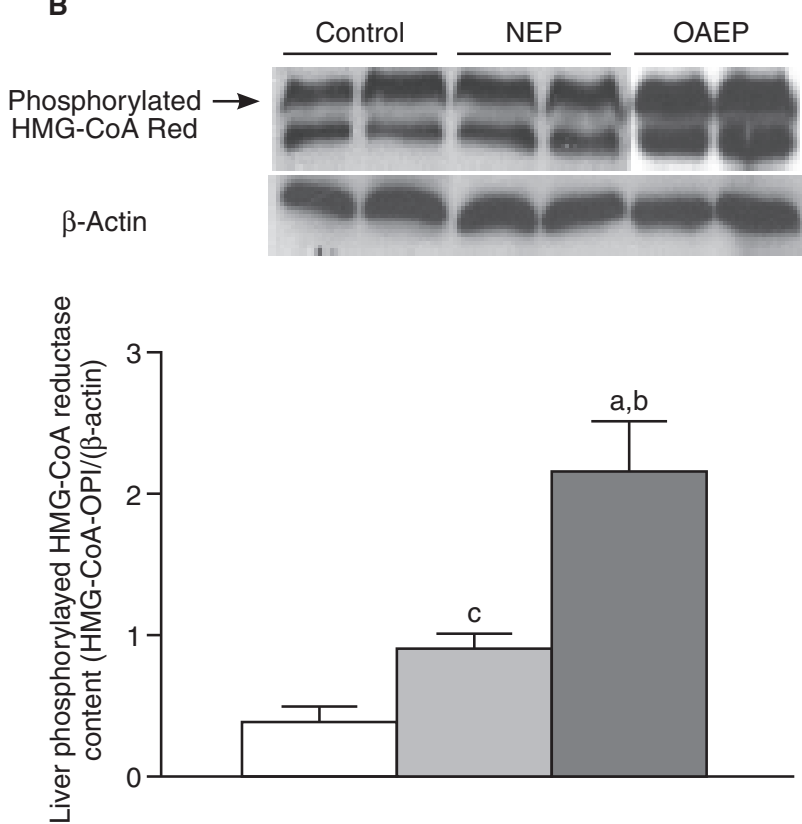

Figure 6

Liver protein expression of total (A) and phosphorylated (B) 3-hydroxy-3-methylglutaryl coenzyme A reductase (HMG-CoA red) in rats after daily administration of either vehicle for policosanol dispersion (control), non-esterified policosanol (NEP; $100 \mathrm{mg} / \mathrm{kg}$ ), or oleic acid esterified policosanol (OAEP; $164 \mathrm{mg} / \mathrm{kg}$ ) for five weeks. Upper panels show representative blots of total HMG-CoA red (97 kDa) and $\beta$-actin $(43 \mathrm{kDa})(\mathrm{A})$ and phosphorylated HMG-CoA red $(98 \mathrm{kDa})$ and $\beta$-actin $(\mathrm{B})$ expression using $60 \mu \mathrm{g}$ of soluble protein. Lower panels show the respective densitometric quantification expressed as total HMG-CoA red/ $\beta$-actin $(A)$ and phosphorylated HMG-CoA $\mathrm{red} / \beta$-actin (B) ratios to compare lane-to-lane equivalence in total protein content. Data are means \pm SEM for the number of animals indicated in parentheses. Statistical significance $(P<0.05)$ is shown by the letters identifying each experimental group, assessed by one-way ANOVA followed by Newman-Keuls' post-test. 
However, previous studies have reported (i) the presence of comparable levels of plasma cholesterol in postmenopausal women before and after consumption of high oleic acid sunflower oil for 28 days (Sánchez-Muniz et al., 2002); and (ii) the lack of effects of the partial exchange of palmitic acid for oleic acid in healthy, normocholesterolemic humans $(\mathrm{Ng}$ et al.,1992; Choudhury et al., 1995) and cebus monkeys (Hayes and Khosla, 1992), suggesting that oleic acid is neutral with respect to plasma cholesterol homeostasis.

Regarding the mechanisms underlying the hypocholesterolemic action of policosanol, Singh et al. (Singh et al., 2006) found increased amounts of phosphorylated AMP-kinase after the incubation of hepatoma cells with policosanol. These authors postulated that policosanol inactivates HMG-CoA red by promoting its phosphorylation by AMP-kinase, in agreement with data reported by Oliaro-Bosso et al. in HUVEC and HepG2 cells (Oliaro-Bosso et al., 2009). Despite the evidence that phosphorylated AMP-kinase decreases HMG-CoA red activity, this kinase plays a central role in the regulation of energy homeostasis, regulating several enzymes involved in glucose and lipid metabolism (Wong et al., 2009). Therefore, we decided to quantify directly the phosphorylated HMG-CoA red, instead of AMPkinase, in order to establish a possible relationship between policosanol administration and HMG-CoA red activity. The data presented indicate that supplementation with NEP or OAEP did not significantly alter the amount of total HMG-CoA red protein compared to control values, whereas OAEP increased the phosphorylated form of the enzyme, in agreement with the reduction in the total and LDLcholesterol concentrations in serum, an effect that is not observed for NEP.

\section{CONCLUSION}

The present study shows that OAEP is more bioavailable and effective than NEP in reducing plasma total and LDL-cholesterol in normocholesterolemic rats, in association with HMG-CoA red inactivation through OAEP-induced phosphorylation. Alternative mechanisms for the cholesterol-lowering action of OAEP, namely, enhancement in both bile acid excretions due to $7-\alpha$-hydroxylase up-regulation and/or clearance of LDL-cholesterol due to higher cellmembrane LDL receptor availability, are currently under study in our laboratory. Considering that this is the first investigation using an esterified policosanol in replacement of the conventional mixture (NEP), additional studies are needed to fully understand their digestion, absorption, and metabolism in the body.

\section{ACKNOWLEDGEMENTS}

The work was supported by grant 1090020 from FONDECYT, Chile. DH was supported by fellowship TPI-27 from PBCT, Chile.

\section{REFERENCES}

Arruzazabala ML, Noa M, Menéndez R, Mas R, Carbajal D, Valdes S, Molina V. 2000. Protective effect of policosanol on atherosclerotic lesions in rabbits with exogenous hypercholesterolemia. Braz. J. Med. Biol. Res. 33, 835-840.

Batista J, Stusser R, Saez F, Pérez B. 1996. Effect of policosanol on hyperlipidemia and coronary heart disease in middle-aged patients. A 14-month pilot study. Int. J. Clin. Pharmacol. Ther. 34, 134-137.

Berthold H, Unverdoeben S, Degenhardt R, Bulitta M, Gouni-Berthold I. 2006. Effect of lipids policosanol on lipid levels among with hypercholesterolemia or combined hyperlipidemia. JAMA. 295, 2262-2269.

Brockerhoff H. 1970. Substrate specificity of pancreatic lipase: Influence of the structure of fatty acids on the reactivity of esters. Biochim. Biophys. Acta. 212, 92101.

Buhman KK, Accad M, Novak S, Choi RS, Wong JS, Hamilton RL, Turley S, Farese RV Jr. 2000. Resistance to diet-induced hypercholesterolemia and gallstone formation in ACAT2-deficient mice. Nat. Med. 6, 13411347.

Castaño G, Mas R, Arruzazabala ML, Noa M, Illnait J,Fernandez JC, Molina V, Menendez A. 1999. Effects of policosanol and pravastatin on lipid profile, platelet aggregation and endothelemia in older hypercholesterolemic patients. Int. J. Clin. Pharm. Res. 19, 105-116.

Castaño G, Mas R, Fernández L, Fernández JC, Illnait J, López LE, Alvarez E. 2000. Effects of policosanol on postmenopausal women with type II hypercholesterolemia. Gynecol. Endocrinol. 14, 187-195.

Castaño G, Mas R, Fernández L, Illnait J, Gámez R, Alvarez E. 2001. Effects of policosanol 20 versus $40 \mathrm{mg} /$ day in the treatment of patients with type II hypercholesterolemia: a 6-month double-blind study. Int. J. Clin. Pharmacol. Res. 21, 43-57.

Castaño G, Mas R, Fernández L, Illnait J, López E, Gamez R, Mendoza S, Fernández J, Mesa M. 2003. Effects of D-003 on the lipid profile of patients with type II hypercholesterolemia: a phase II clinical study. Clin. Drug Investig. 23, 789-802.

Choudhury N, Tan L, Truswell AS. 1995. Comparison of palmolein and olive oil: effects on plasma lipids and vitamin $\mathrm{E}$ in young adults. Am. J. Clin. Nutr. 61, 10431051.

Clifton P. 2009. Lowering cholesterol - a review on the role of plant sterols. Aust. Fam. Physician 38, 218221.

Crespo N, Illnait J, Mas R, Fernández L, Fernández JC, Castaño G. 1999. Comparative study of the efficacy and tolerability of policosanol and lovastatin in patients with hypercholesterolemia and noninsulin dependent diabetes mellitus. Int. J. Clin. Pharmacol. Res. 29, 117127.

Dulin M, Hatcher L, Sasse H, Barringer T. 2006. Policosanol is ineffective in the treatment of hypercholesterolemia: a randomized controlled. Am. J. Clin. Nutr. 84, 15431548.

Francini-Pesenti F, Brocadello F, Beltramolli D, Nardi M, Caregaro L. 2008a. Sugar cane policosanol failed to lower plasma cholesterol in primitive, diet-resistant hypercholesterolaemia: a double blind, controlled study. Complement Ther. Med. 16, 61-65.

Francini-Pesenti F, Beltramolli D, Dall'acqua S, Brocadello F. 2008b. Effect of sugar cane policosanol on lipid 
profile in primary hypercholesterolemia. Phytother. Res. 22, 318-322.

González-Bravo L, Magraner-Hernández J, AcostaGonzalez PC, Pérez-Souto N. 1996. Analytical procedure for the determination of 1-octacosanol in plasma by solvent extraction and capillary gas chromatography. J. Chromatogr. B Biomed. Appl. 682, 359-363.

Gouni-Berthold I, Berthold HK. 2002. Policosanol: clinical pharmacology and therapeutic significance of a new lipid-lowering agent. Am. Heart J. 143, 356-365.

Greyling A, DeWitt C, Oosthuizen W, Jerling J. 2006. Effects of a policosanol supplement on serum lipid concentrations in hypercholesterolemic and heterozygous familial hypercholesterolemic subjects. Br. J. Nutr. 95, 968-975.

Haim D, Berrios M, Valenzuela A, Videla L. 2009. Trace quantification of 1-octacosanol and 1-triacontanol and their main metabolites in plasma by liquid-liquid extraction coupled with gas chromatography mass spectrometry. J. Chromatogr. B. Biomed. Appl. 887, 4154-4158.

Haim D, Videla L. 2008. Policosanols, protective natural compounds in cardiovascular disease. Agro Food Industry Hi-Tech. 19, 60-63.

Hargrove JL, Greenspan P, Hartle DK. 2004. Nutritional significance and metabolism of very long chain fatty alcohols and acids from dietary waxes. Exp. Biol. Med. 229, 215-226.

Hayes KC, Khosla P. 1992. Dietary fatty acid thresholds and cholesterolemia. FASEB J6, 2600-2607.

Hernandez F, Illnait J, Mas R. 1992. Effect of policosanol on serum lipid and lipoproteins in healthy volunteers. Curr. Ther. Res. Clin. Exp. 51, 568-575.

Janikula M. 2002. Policosanol: a new treatment for cardiovascular disease? Altern. Med. Rev. 7, 203-217.

Kabir Y, Kimura S. 1993. Biodistribution and metabolism of orally administered octacosanol in rats. Ann. Nutr. Metab. 37, 33-38.

Kassis AN, Jones PJ. 2006. Lack of cholesterol-lowering efficacy of Cuban sugar cane policosanols in hypercholesterolemic persons. Am. J. Clin. Nutr. 84, 1003-1008.

Kassis AN, Marinangeli CP, Jain D, Ebine N, Jones PJ. 2007. Lack of effect of sugar cane policosanol on plasma cholesterol in Golden Syrian hamsters. Atherosclerosis 194, 153-158.

Keller S, Gimmler F. 2008. Octacosanol administration to humans decreases neutral sterol and bile acid concentration in feces. Lipids. 43, 109-115.

Laemmli UK. 1970. Cleavage of structural proteins during the assembly of the head of bacteriophage T4. Nature. 227, 680-685.

Marrero D, González-Bravo L. 2001. Trace determination of 1-octacosanol in rat plasma by solid-phase extraction with Tenax GC and capillary gas chromatography. J. Chromatogr B. Biomed. Appl. 762, 43-49.

Mas R, Castaño G, Illnait J, Fernandez L, Fernandez J, Aleman C, Pontigas V, Lescay M. 1999. Effects of policosanol in patients with type II hypercholesterolemia and additional coronary risk factors. Clin. Pharmacol. Ther. 65, 439-447.

Mendoza S, Gamez R, Noa M, Mas R, Castaño G, Mesa R, Mesa MS, Armas M. 2001. Comparison of the effects of D-003 and policosanol on lipid profile and endothelial cells in normocholesterolemic rabbits. Curr. Ther. Res. 62, 209-220.

Menendez R, Amor AM, Gonzalez RM, Fraga V, Mas R. 1996. Effect of policosanol on the hepatic cholesterol biosynthesis of normocholesterolemic rats. Biol. Res. 29, 253-257.
Menéndez R, Amor AM, Rodeiro I, González RM, Gonzalez PC, Alfonso JL, Mas R. 2001. Policosanol modulates HMG-CoA reductase activity in cultured fibroblasts. Arch. Med. Res. 31, 8-12.

Menéndez R, Marrero D, Más R, Fernández I, González L, González RM. 2005. In vitro and in vivo study of octacosanol metabolism. Arch. Med. Res. 36, 113-119.

Murphy KJ, Saint DA, Howe PR. 2008. Lack of effect of sugar cane and sunflower seed policosanols on plasma cholesterol in rabbits. J. Am. Coll. Nutr. 27, 476-484.

$\mathrm{Ng}$ TK, Hayes KC, DeWitt GF, Jegathesan M, Satgunasingam N, Ong AS, Tan D. 1992. Dietary palmitic acid and oleic acid exert similar effects on serum cholesterol and lipoprotein profiles in normocholesterolemic men and women. J. Am. Coll. Nutr. 11, 383-390.

$\mathrm{Ng}$ Chi H, Leung Ka Y, Huan Y, Cehn Zhen Y. 2005. Policosanol has no antioxidant activity in human lowdensity lipoprotein but increases excretion of bile acids in hamsters. J. Agric. Food Chem. 53, 6289-6293.

Nissinen MJ, Gylling H, Miettinen TA. 2006. Effects of plant stanol esters supplied in a fat free milieu by pastilles on cholesterol metabolism in colectomized human subjects. Nutr. Metab. Cardiovasc. Dis. 16, 426-435.

Oliaro-Bosso S, Calcio Gaudino E, Mantegna S, Giraudo E, Meda C, Viola F, Cravotto G. 2009. Regulation of HMG-CoA reductase activity by policosanol and octacosadienol, a new synthetic analogue of octacosanol. Lipids. 44, 907-916.

Place AR. 1992. Comparative aspects of lipid digestion and absorption: physiological correlates of wax ester digestion. Am. J. Physiol. 263, R464-R471.

Pons P, Mas R, Illnait J, Fernandez L, Rodriguez M, Robaina C, Fernández JC. 1992. Efficacy and safety of policosanol in patients with primary hypercholesterolemia. Curr. Ther. Res. Clin. Exp. 52, 507-513.

Prat $\mathrm{H}$, Roman O, Pino E. 1999. Comparative effects of policosanol and two HMG-CoA reductase inhibitors on type II hypercholesterolemia. Rev. Med. Chile 127, 286-294.

Sánchez-Muniz FJ, Cruz-Merinero M, Rodríguez-Gil S, Ordovás JM, Ródenas S, Cuesta C. 2002. Dietary fat saturation affects apolipoprotein All levels and HDL composition in postmenopausal women. J. Nutr. 132, 50-54.

Singh BK, Mehta JL. 2002. Management of dyslipidemia in the primary prevention of coronary heart disease. Curr. Opin. Cardiol. 17, 503-511.

Singh D, Li L, Porter T. 2006. Policosanol inhibits cholesterol synthesis in hepatoma cells by activation of AMP kinase. J. Pharm. Exp. Therap. 318, 1020-1026.Torres O, Agramonte AJ, Más R, Fernández L, Fernández JC. 1995. Treatment of hypercholesterolemia in NIDDM with policosanol. Diabetes Care. 18, 393-397.

Towbin H, Staehelin T, Gordon J. 1979. Electrophoretic transfer of proteins from polyacrylamide gels to nitrocellulose sheets: procedure and some applications. Proc. Natl. Acad. Sci. USA. 76, 4350-4354.

Wong AK, Howie J, Petrie JR, Lang CC. 2009. AMPactivated protein kinase pathway: a potential therapeutic target in cardiometabolic disease. Clin. Sci. 16, 607-620.

Wu T, Fu J, Yang Y, Zhang L, Han J. 2009. The effects of phytosterols/stanols on blood lipid profiles: a systematic review with meta-analysis. Asia Pac. J. Clin. Nutr. 18, 179-186.

Recibido: $10 / 1 / 12$ Aceptado: 16/5/12 